\title{
Managing Patron-Driven Acquisitions (PDA) Records in a Multiple Model Environment
}

\author{
Daniel C. Draper \\ University Libraries, Colorado State University, Fort Collins, CO
}

Academic libraries have widely embraced patron-driven acquisition (PDA) models for electronic and print books. Vendors supply title level MARC records to facilitate discovery through library catalogs, and managing these records can be challenging. Colorado State University Libraries (CSUL) implemented four PDA models over the past two years. Since these records constitute a growing portion of the collection, CSUL recognizes the importance of developing careful record management policies and workflows to handle various acquisitions models. In this article the author describes the four PDA models, the cataloging policies and processes, and staffing levels needed for managing the records.

Keywords: patron-driven acquisitions, demand-driven acquisitions, MARC record loads, batch-loading, records management, electronic books

Academic libraries have widely instituted patron-driven acquisition (PDA), also known as demanddriven acquisition (DDA) services. These services allow libraries to reduce acquisition costs while increasing access to their electronic and print collections. Book aggregators and publishers deliver these services through their platforms and supply machine-readable cataloging (MARC) records for these services, thus assisting patron discovery of PDA materials through library catalogs. At Colorado State University Libraries (CSUL), we have implemented various models for acquiring monographs as PDA, three involving e-books and one for books in print. As a result, records management for vendorsupplied MARC records has become complicated in distinguishing between different sources, keeping different files separate, and preventing multiple records for the same book. As the number of PDA MARC records at CSUL approaches 40,000 and the models and records overlap, CSUL has found that the interrelationships between the PDA record batches require greater planning and scrutiny than loading other batch bibliographic records. In contrast to other batches, CSUL has decided not to load PDA records as a final product. Instead they are initially added as discovery records, upgraded if they are purchased, and removed when necessary if the vendor no longer carries the title. As academic libraries increase their number of PDA services, libraries must develop clear policies and workflows to ensure 
that these bibliographic records are managed effectively so staff can handle them efficiently and users can access the materials they need without confusion.

\section{Literature Review}

Numerous studies have focused on PDA acquisitions, collection development, and patron usage studies; little, however, has been written on records management. Nixon et al. (2010), for example, trace the history of the PDA literature from its conceptual beginnings in the 1970s through 2010 and the emergence of e-book vendor relationships with libraries when vendors began delivering e-book records in conjunction with databases. But the authors say little at all about managing records. Perhaps as close as they come to the problem of records management is the authors' suggestion that Internet users' relative ease in purchasing print titles from online stores has nicely carried over to selecting a PDA ebook from library catalogs. Levine-Clark (2010) discusses the planning of the University of Denver's Penrose Library multi-format PDA services with YBP but mentions record management only in passing. The Penrose Library system includes loading both electronic and print MARC records in the library catalog. When a patron discovers a PDA record in the catalog, a link is provided to connect with the content at the vendor's site. The initial vendor webpage offers more book information and gives a link to the full text.

In the June 2011 issue of Against the Grain, dedicated entirely to PDA, only two articles touch on records management. Spitzform (2011) describes the University of Vermont Libraries' implementation of PDA services for print materials in 2007, which uses MARC records delivered from YBP. McElroy and Hinken (2011) delve a bit more into records management when they discuss creating a collaborative PDA partnership between the Orbis Cascade Alliance and YBP. The alliance found YBP's Global Online Bibliographic Information $\left(\mathrm{GOBI}^{\circledR}\right)$ system advantageous for managing title selection, for handling financial transactions, and for clearly designating when titles switched from long-term loans to purchases. 
A recent publication provides provocative studies of PDA at academic libraries and delves more deeply into problems of records management. Although Walters (2012) argues that "PDA programs are unlikely to improve the quality of academic library collections" (p. 199), in his review of PDA literature and effort to create principles for evaluating PDA programs, he is very aware of bibliographic control problems with PDA services and possible patron frustration over inconsistent catalog information. In particular, he notes that some PDA materials such as those in print are not always accessible immediately, and some catalogs include incomplete and inaccurate vendor-supplied MARC records. Walters concludes that these, "cataloging issues ... may impede information discovery and reduce patrons' confidence in the library" (p. 209).

A number of publications focus on certain aspects of record management. Hodges et al. (2010) writes about two 2009 Ohio State University Libraries (OSUL) pilot projects with ebrary. Both pilots included receipt of vendor-delivered MARC records. The authors describe local practices in loading the records into the Innovative Interfaces, Inc. (Innovative) Millennium Integrated Library System (ILS). MarcEdit was used to manipulate and append metadata prior to loading, and a loader was constructed to add fixed-field metadata and attach an item record to each loaded bibliographic record. All the PDA records were made accessible to OSUL, the library interface, but they were not contributed to either OhioLINK or WorldCat. Nabe and Imre (2011) discuss Southern Illinois University-Carbondale's implementation of a purchase-on-demand acquisitions agreement with MyiLibrary. MARC record batches were provided from MyiLibrary, and the batches are reviewed and edited before loading them into the library catalog. The authors state that the records do not have OCLC numbers in the 001 MARC field, and they argue that this omission creates more work for catalogers after the book is purchased, because the correct corresponding OCLC number needs to be found before setting OCLC holdings. Additionally, the authors argue for the importance of the International Standard Book Number (ISBN) 
for matching between print and electronic versions, and they encourage vendors to be thorough in adding ISBNs to help libraries reconcile overlap between collections and e-book providers.

Booth and O'Brien (2011) discuss a few complications in sharing consortia MARC records, including what decisions must be made regarding Interlibrary Loan (ILL), who will fully catalog purchased materials, and who sets OCLC holdings. Dinkins (2012) explains how Stetson University's duPont-Ball Library manages ebrary-supplied MARC records. She describes how to designate temporary records and select statistic fields in the library's SirsiDynix ${ }^{\circledR}$ ILS. Dinkins also discusses complications with the vendor-supplied MARC record batches.

Loading vendor-supplied MARC records is a major component in managing PDA records. Two recent studies provide insight into academic library batch-record load practice. Mugridge and Edmunds (2012) describe bibliographic record-load survey results of 18 large research libraries. Although batch-records improve library catalog resource discovery, the record quality is often inconsistent. The authors report that $82.4 \%$ of surveyed libraries "... use of vendor-supplied metadata for digital resources had lowered local quality standards for bibliographic data" (p. 161). Libraries generally use programs and text editors (e.g. MarcEdit) to make record batches more consistent and to correct problems. The authors note that libraries and vendors are working to improve record batches and better align with national standards, including the 2009 MARC Record Guide for Monograph Aggregator Vendors, $2^{\text {nd }}$ edition.

Young (2012) conducted a batch-cataloging survey and gathered 128 library respondent practices and problems. Most respondents receive record batches from vendors or aggregators; fewer used Z39.50 protocol and OCLC Connexion. Additionally, the author found that libraries frequently revise records prior to loading with text editors, and loaders are often customized for specific record batches. Young states that "Those performing batch cataloging will need to build on their cataloging knowledge to learn new tools and methods of manipulating large groups of records" (p. 37). 


\section{PDA Records Management Models at Colorado State University Libraries}

CSUL has implemented four models involving PDA and loading records into the online catalog.

Three of these models involve e-books, and the fourth involves loading records into the catalog for print books that would have been received on the approval profiles.

In April 2010, CSUL set up a pilot project with Ebook Library (EBL), a major aggregator of e-books, to load discovery records into the online catalog for the publishers Wiley, CABI, and Routledge. The records were vendor records supplied by EBL and are not upgraded until there is an automatic purchase. Even though there was some concern on the part of catalogers regarding the quality of the record, users appeared to find records without noticeable issues. As with all its PDA projects for e-books from EBL, CSUL allows the patron to have four short-term loans before an automatic purchase is generated. With EBL, CSUL chose the non-linear or 325 simultaneous uses per year model when the book is purchased.

In August 2011, economic factors and low use statistics for print books nudged CSUL to replace its traditional approval plans with patron driven e-book selection for all subjects received on approval plan profiles except for history, art, English literature, and veterinary sciences, which is an area of excellence at CSU. CSUL's approval plan vendor is YBP, a vendor that works with both EBL and ebrary. As a result, CSUL stopped the direct shipment of records from EBL for the three publishers and instead received records from YPB for any e-book EBL supplies that matches a profile on the approval plan. Instead of vendor records from EBL, however, YBP supplies records from its $\mathrm{GOB}{ }^{\circledR}$ Plus program.

To add another layer to the process, in May 2012, CSUL began to participate in a shared e-book project through the Colorado Alliance of Research Libraries (Alliance) and began loading $\mathrm{GOBI}^{\circledR}$ Plus records supplied by YBP into its online catalog for publishers selected by the Alliance libraries. Each participating library has agreed to follow similar loading and cataloging procedures for the Alliance project. Each library loads the files received from YPB into its local catalog and also uploads the records into the regional catalog for the Alliance, known as Prospector. When an item is purchased within the 
Alliance, CSUL serves as the lead library to catalog the record by upgrading an OCLC record and notifying the other Alliance libraries. Later this year, the Alliance plans to add a group of publishers supplied by ebrary. To prevent duplication with local plans, each library blocks these publishers from its local approval plan.

A fourth project is the PDA print project CSUL began with YPB in November, 2011. Except for the four profiles for which CSUL still receives the print book, YPB sends CSUL a record based on one harvested from OCLC for all the titles that would have been received as books on the approval plan, with the expectation that the user can request that the library purchase a print version of the book if that is needed. Furthermore, CSUL knowingly duplicates records for e-books with records for print books to allow the user to choose the format and has had no problems or unexpected expenditures as a result. YPB provides a record for CSUL that has a link to a locally programmed order form in the 856 field that allows users to choose whether to order the title as a rush or from the regional catalog if available.

\section{CSUL Policies for PDA MARC Records}

In order to make the management of these models as efficient as possible, CSUL created similar cataloging policies for all of its PDA-delivered MARC records. These policies reflect the fact that CSUL continues to experience staff decreases in the technical services area and must find economies in processing and cataloging whenever possible. A variety of approaches were employed to find simple, effective ways to manage PDA records with a focus on quick patron delivery. A critical decision was to accept all discovery records "as is" without upgrading the cataloging until a title is selected for purchase. This means that regardless of cataloging encoding level, whether or not a record has classification, or whether a book has received subject analysis, the discovery record will not be changed. As noted previously, CSUL has not heard serious concerns expressed by users about finding the title they want based on the quality of the record. Also, the vendors are aware of issues surrounding the quality of discovery records and are working to improve the quality of these records. When patrons select a PDA 
record for purchase, acquisitions staff members retrieve an OCLC record and upgrade the bibliographic record to a full-cataloging encoding level and attach order and item records. CSUL has established checklists for upgrading selected fields for e-books, so this is an efficient process that fits into the fast cataloging workflows. Currently, the number of titles purchased after four short-term loans is small, so the title-by-title upgrading of the record is manageable; however, this policy may need future review of methodology if the number of books purchased increases significantly.

Another critical decision involved using the 001 MARC and other fields to identify the source of the discovery record. According to MARC standards, the 001 field is a control number field. CSUL generally uses it for OCLC numbers, but in this case CSUL is asking vendors to supply the provider number in the 001 when the vendor sends the discovery record to the library. Since CSUL uses only numeric string identifiers for OCLC numbers, all other control numbers are assigned a unique alpha prefix, e.g. EBL446811 for EBL numbers and ybp6964839 for YBP numbers, providing a consistent way to identify each vendor control number and preventing potential overlay with OCLC numbers. These control numbers are replicated in 035 MARC fields, and other pertinent control numbers are added to 035 fields when necessary.

In addition to control numbers, CSUL adds a local 944 field to each batch-loaded record that gives a specific batch group name and the load date, e.g. "EBL Patron Driven mm/dd/yyyy" is used for each EBLdelivered record. This load date can later be used to harvest records for possible deletion if the records are never accessed, or for other maintenance. The 944 field is removed when a record is upgraded after being selected for purchase.

CSUL also adds a collection field to all batch-load records, so the records can be harvested through the patron interfaces through the title index. PDA record projects use Shibboleth ${ }^{\circledR}$ authentication; these are the first CSUL catalog records to use this federated identity solution. Shibboleth ${ }^{\circledR}$ uses the CSU electronic identification (eid), which intentionally restricts PDA to CSU faculty, staff, and students. For 
each e-book record, the loader adds the public note "Access online version" that displays in place of the uniform resource locator (URL). These policies provide uniform structure to all PDA-delivered records and assist in long-term management.

\section{Implementing PDA Models with Loaders}

After determining the type of cataloging records and local fields CSUL wanted to use, CSUL consulted with the vendors (both EBL and YBP) to see what they could provide in the records that they sent. Vendors can offer helpful advice since they have had experience working with other libraries and are also willing to test new services that might become a marketing tool for the vendor. Although extensive customization cannot be expected for discovery records, the vendors were willing to supply a certain number of additional fields and values. Otherwise, the library would have had to add the fields and data through its local loader. In addition to its standard list of fields, the vendor supplied the following fields and values for CSUL for its e-book records:

- 001 YBP unique identifier

- 035 YBP unique identifier

- 440 Series title: Ebook Library (EBL)

- 538 System requirements

- 538 Mode of Access: World Wide Web

- 690 Electronic monograph

- 856 URL for online access of the book 


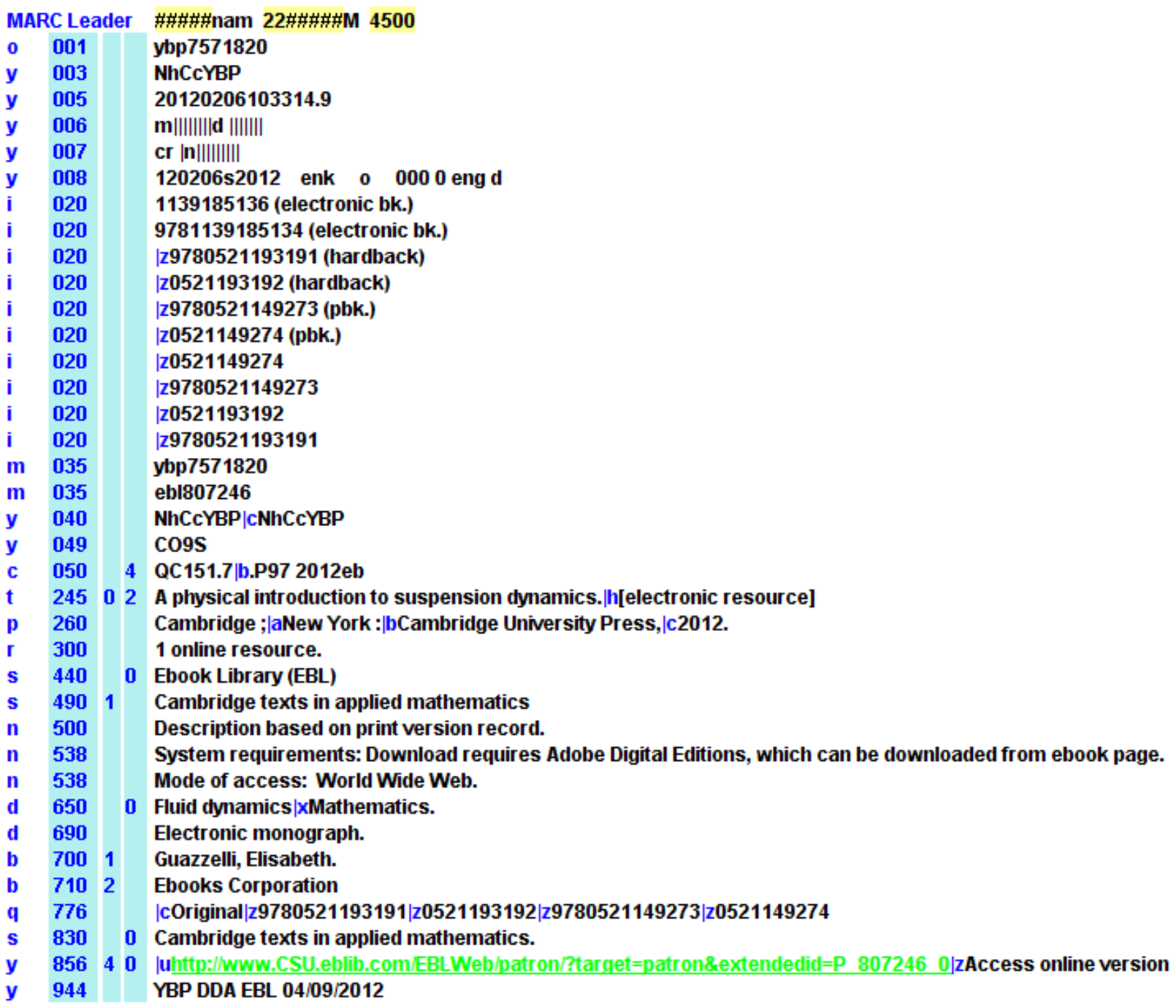

In the project with the Alliance of Research Libraries, YPB allowed the group to add three notes fields,

which include:

- 538 Book preview interface supplied PDF, image or read aloud access. Adobe Digital Editions software required for book downloads.

- 538 Users at some libraries may be required to establish an individual no charge EBL account, and log in to access the full text. For security, do not use a confidential or important ID and password to log in; create a different username and password.

- 540 Books may be viewed online or downloaded (to a maximum of two devices per patron) for personal use only. No derivative use, redistribution or public performance is permitted. Maximum usage allowances loan period: 7 days for some publishers; printing: up to 20 percent of the total pages; copy/paste: up to 5 percent of the total pages. 


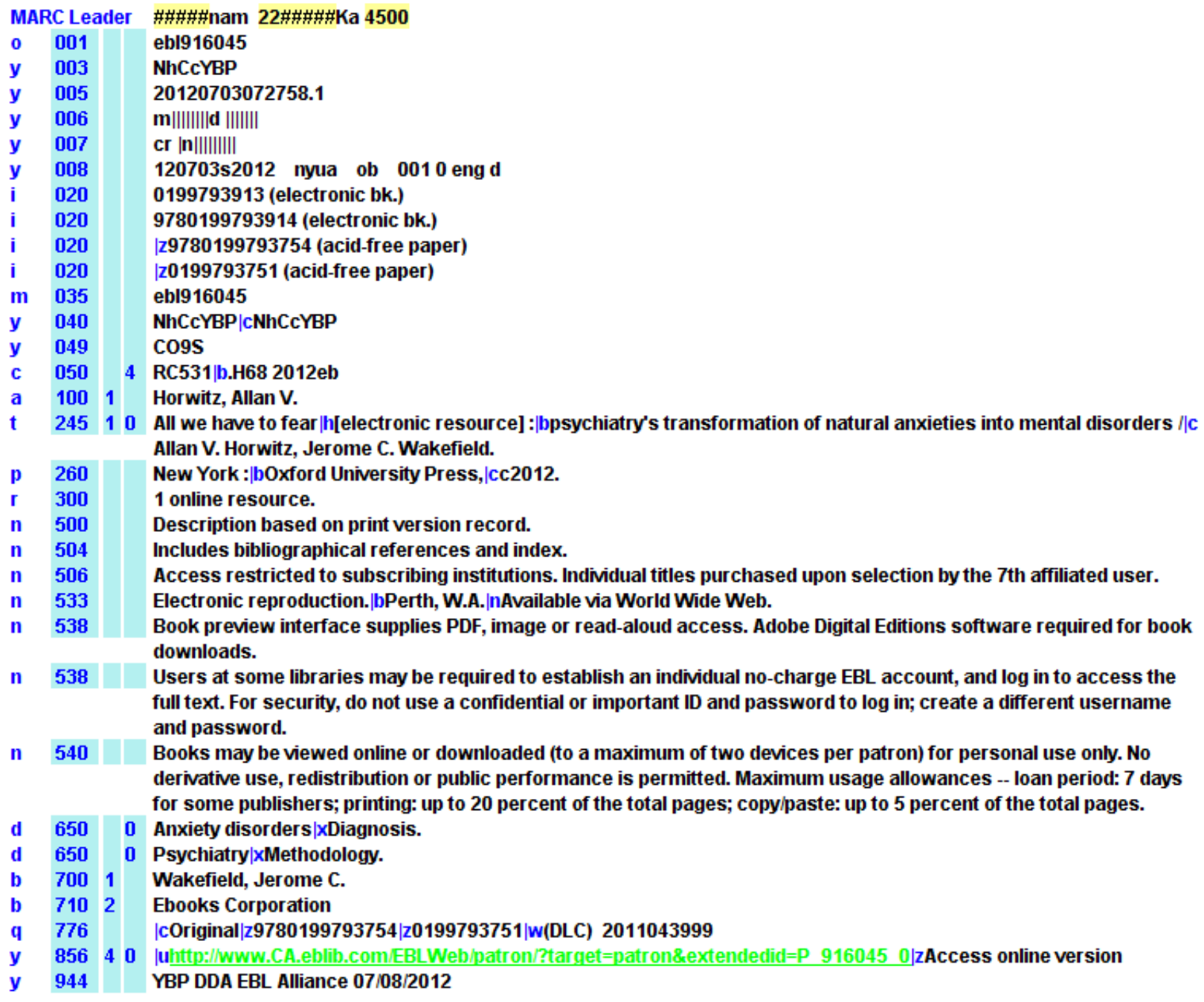

For the print DDA, the following fields are added:

- 440 Series title: YBP Print DDA

- 856 URL to order print monograph with the public note: This book is available for the library to purchase in print. Click here to place a request.

- 960 Number of volumes, price, location, PDA profile, vendor, and currency

- 961 CSUL staff code, manifestation

- 984 Date, vendor profile number and vendor

- 987 YBP unique identifier 
Illustration 3: YBP Print PDA Record Example

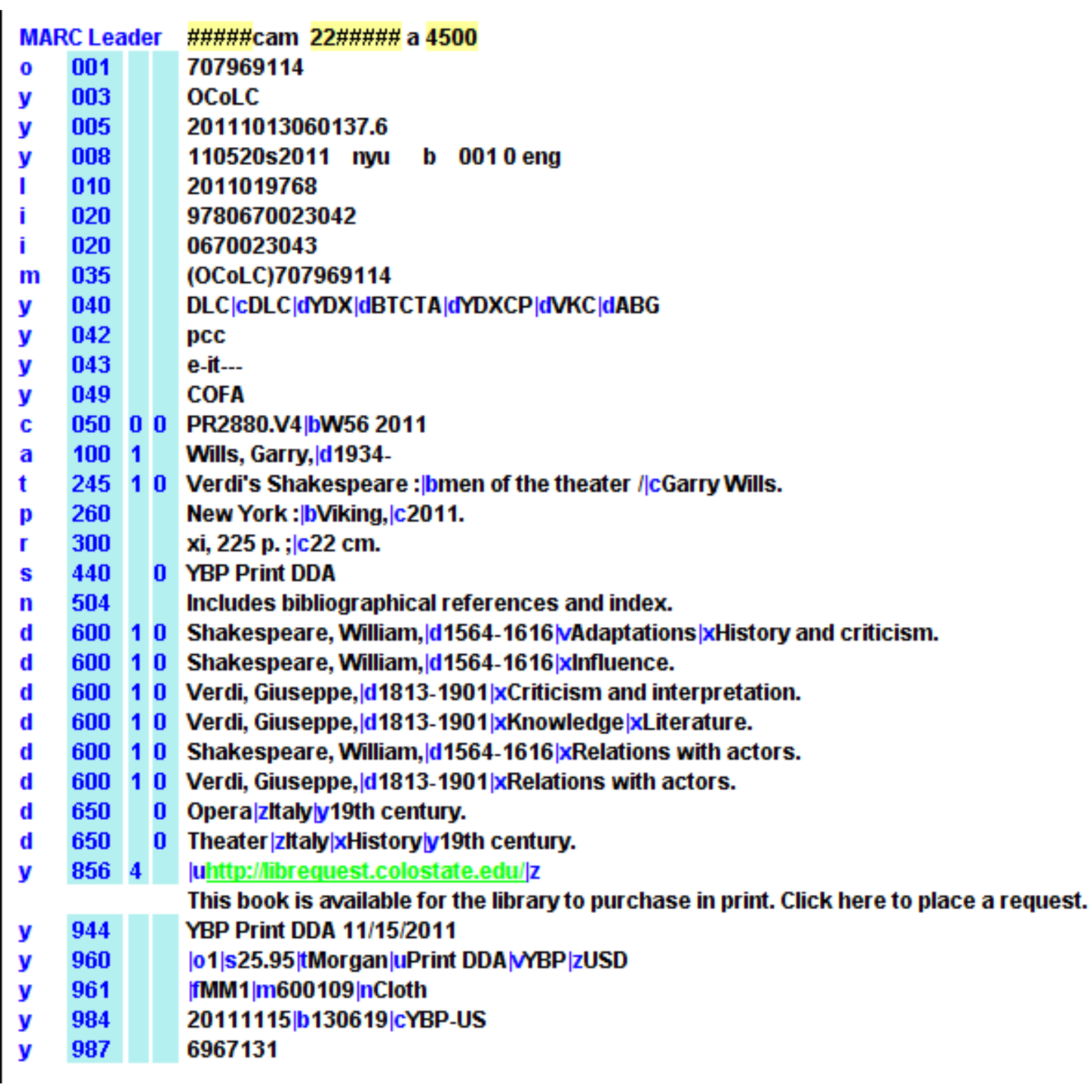

After CSUL and the vendor agreed on what fields the vendor would supply for a particular model, the Metadata Librarian in charge of designing and developing loaders for CSUL's Innovative ILS quickly adapted an existing bibliographic loader to handle the records. As every library knows, loaders are an efficient way to add records quickly and are used often for a variety of record types. CSUL has always used a professional cataloger, who receives loader training at an extensive course held by Innovative, to design loaders and handle batch loads for bibliographic data. CSUL assigns routine loading to 
paraprofessional staff who work closely with a particular function such as circulation or acquisitions. This arrangement works well for quickly creating MARC loaders.

The implementation of the Alliance discovery records required staff to determine how loaders for the three PDA e-book record groups would interact to catch duplication. Since all three groups have 035 MARC field match points with EBL numbers, CSUL decided to have Alliance records overlay the locally loaded e-book PDA records if there was a match on the EBL number; likewise, the record coming from the local CSUL approval profile plans should not overlay the Alliance records. The most effective way to manage this overlay was through the loader. Staff programmed a catalog encoding-level hierarchy in the loaders that set full catalog encoding (blank, I and 1) at the top with ' $K$ ' next and ' $M$ ' as the lowest level. This program ensures that records from lower encoding levels will not overlay higher catalog encoding levels. All CSUL e-book PDA discovery records are changed to catalog encoding level ' $\mathrm{M}$ ', the Alliance records are changed to catalog encoding level ' $\mathrm{K}$ ', and the purchased records are changed to a full-level record. Changing the catalog encoding levels automatically through the loader means that additional indexing needs to be purchased from Innovative. The added ability allows the loader to change the MARC Leader's byte 17 to a specific code. Furthermore, the system is programmed to reject any matches on lower catalog encoding levels and annotate the rejected matches. Therefore, CSUL staff members are able to see if a CSUL discovery record attempted to overlay an Alliance discovery record, or if a discovery record attempted to overlay a purchased record which was fully cataloged with an OCLC number in the 001 field.

\section{Constructing Workflows}

In order to process the various files that needed to be loaded efficiently, CSUL developed clear workflows for staff to follow. Timely processing is essential to avoid backup of the files received weekly; in addition, participation in a consortia arrangement obligates a library to maintain its commitment to load records in a specific timeframe so all users of the consortia's libraries have equal access to the 
records. CSUL receives three PDA batches weekly, automatic purchase notifications daily, and deletion batches monthly. To handle these varied workflows in a timely manner, trained staff members are needed to conduct these ongoing workflows.

To handle records for approval shipments and notification of purchases, staff members need proficiency in both acquisitions and cataloging. CSUL's acquisitions staff members are best positioned for managing these duties, since they are skilled copy catalogers and have experience processing similar approval plan materials. Therefore, they are trained to manage all aspects of the responsibilities from running the loaders to upgrading purchases to dealing with vendor-related problems, such as delays in receipt of files or strange records. CSUL has three separate workflows that allow the work to be delegated and easily transferred among trained staff members. CSUL finds intuitive workflows with clearly written instructions and supplemented with screenshots, help staff navigate through multiple systems. CSUL's workflows include:

Weekly Load Workflow

- Receive notifications: CSUL created a generic email that is received by all pertinent staff members. This allows the work to be completed by other staff if one person is not available.

- Retrieve file from vendor: the e-book batches are delivered to YBP's File Transfer Protocol (FTP) location, and the print PDA batches are retrieved through $G O B I^{\circledR}$.

- Change load date (944 MARC field) through Innovative's INNOPAC system.

- Upload file and load through Innovative's Millennium system (Data Exchange)

- Annotate record statistics (date, file name, number of records, bibliographic record range)

\section{Cataloging Purchases Workflow}

- Receive purchase alerts via email.

- Create and attach order record to discovery bibliographic record.

- Catalog record fully using CSUL's cataloging checklists in OCLC (use macros) and overlay discovery bibliographic record.

- Pay invoice after receipt from vendor.

\section{Deletion Batch Workflow}

An additional workflow was created to manage EBL's monthly deletion batches for materials removed from their database. CSUL staff finds the most effective way to handle this work is through a loader. 
When the records are loaded, they overlay the library catalog's existing records, suppress the records, and add a local 946 delete note. The records are then harvested through Innovative Millennium's Create Lists function and processed through the Delete Records function. CSUL finds it essential to the Delete Records criteria of "no attached records" to ensure purchases will not be automatically deleted.

\section{Conclusion}

PDA content and services continue to grow through academic libraries (Esposito, 2012), and vendors will continue to supply title-level MARC records to facilitate discovery through library catalogs. As libraries establish multiple PDA models, records management for vendor-supplied MARC records become complicated in distinguishing between models, managing records, and ensuring the acquisitions components are completed. CSUL has recognized the importance of constructing record management policies and workflows, as these records constitute a growing portion of libraries' collection. Since PDA services with library catalog MARC records are in their infancy, libraries must be prepared for future changes and implications that affect records management. What will be done if PDA records are not accessed? Will they be deleted? And, if so, what time frame should be set for them to remain in the catalog unused? What consequences are there for vendors changing PDA services? What is the impact of libraries ending PDA contracts? And what are the ramifications for vendors changing hands? As academic libraries increase PDA services, it will require planning and forethought to ensure that these bibliographic records are managed effectively.

\section{Acknowledgement}

The author extends his gratitude to Patricia Smith, Collections Coordinator, Colorado State University Libraries for her profound contributions and insight. 


\section{References}

Booth, H. A. \& O’Brien, K. (2011). Patron-driven cooperative collection development: Three studies from the USA. Interlending \& Document Supply, 39(3), 148-155.

Dinkins, D. (2012). Individual title requests in PDA collections: A small university's experience. College \&Research Libraries News, 73(5), 249-255.

Esposito, J. (2012). Sizing the market for patron-driven acquisitions (PDA). Scholarly Kitchen. Retrieved July 23, 2012 from http://scholarlykitchen.sspnet.org/2012/05/08/sizing-the-market-for-patrondriven-acquisitions-pda/

Hodges, D., Preston, C., \& Hamilton, M. J. (2010). Patron-initiated collection development: Progress of a paradigm shift. Collection Management, 35, 208-221.

Levine-Clark, M. (2010). Developing a multiformat patron-driven acquisition model. Collection Management, 35, 201-207.

McElroy, E. \& Hinken, S. (2011). Pioneering partnerships: Building a demand-driven consortium eBook collection. Against the Grain, 23(3), 34-38.

Mugridge, R. \& Edmunds, J. (2012). Batchloading MARC bibliographic records. Library Resources \& Technical Services, 56(3), 155-170.

Nabe, J. \& Imre, A. (2011). Let the patron drive: Purchase on demand of e-books. The Serials Librarian, 60, 193-197.

Nixon, J. M., Freeman, R. S., \& Ward, S. M. (2010). Patron-driven acquisitions: An introduction and literature review. Collection Management, 35, 119-124.

Program for Cooperative Cataloging. (2009). MARC record guide for monograph aggregator vendors. (Includes revisions to September 2011). Retrieved July 30, 2012 from http://www.loc.gov/aba/pcc/sca/documents/FinalVendorGuide.pdf

Spitzform, P. (2011). Patron-driven acquisitions: Collecting as if money and space mean something. Against the Grain, 23(3), 20-24.

Walters, W. H. (2012). Patron-driven acquisition and the educational mission of the academic library. Library Resources \& Technical Services, 56(3), 199-213.

Young, P. (2012). A survey of batch cataloging practices and problems. Technical Services Quarterly, 29(1), 23-41.

Address correspondence to Daniel C. Draper, Metadata Librarian, University Libraries, Colorado State University, Fort Collins, CO 80523-1019. E-mail: ddraper@colostate.edu

Received: August 15, 2012

Accepted: September 5, 2012 